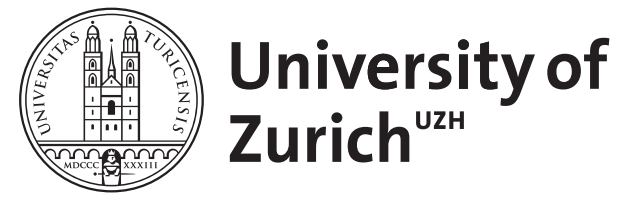
Archive

University of Zurich

University Library

Strickhofstrasse 39

CH-8057 Zurich

www.zora.uzh.ch

Year: 2018

\title{
Introduction to part 4: Observational pragmatics
}

Jucker, Andreas H

DOI: https://doi.org/10.1515/9783110424928-013

Posted at the Zurich Open Repository and Archive, University of Zurich

ZORA URL: https://doi.org/10.5167/uzh-152157

Book Section

Published Version

The following work is licensed under a Publisher License.

Originally published at:

Jucker, Andreas H (2018). Introduction to part 4: Observational pragmatics. In: Jucker, Andreas H; Schneider, Klaus P.; Bublitz, Wolfram. Methods in Pragmatics. Berlin: De Gruyter, 335-342.

DOI: https://doi.org/10.1515/9783110424928-013 


\title{
13. Introduction to part 4: Observational pragmatics
}

\author{
Andreas H. Jucker
}

\section{Introduction}

Parts 4 and 5 of this handbook are devoted to methods of analysis that rely on observational data, that is to say on data that have an existence outside of the research context and which have not been experimentally elicited or created by the researcher. Part 4 focuses on methods of analysis that are mainly qualitative and rely on relatively small sets of data, consisting, for instance, of transcriptions of audio- or video-recorded data, field notes of various types or small samples of written texts. Part 5, in turn, will focus on research methods that are mostly quantitative in nature and depend on larger data samples, which require computer assisted retrieval techniques.

The distinction between qualitative and quantitative research is here used mainly as a convenient structuring principle. It is not a distinction that can be applied in any categorical manner. In a general sense, qualitative approaches focus on functional aspects of linguistic entities; they focus on careful descriptions of generally small sets of data without considering numerical data, such as frequency figures or measurements (Andersen 2011: 587). Patterns and generalisations are described on a small scale. Distributional differences based on statistical information are less important. The focus is very much on the description of the details, on meanings and functions in context.

Quantitative research, on the other hand, is based on numerical data, on measurements and frequencies. Such approaches are generally based on large datasets. Patterns and generalisations are described on a large scale and often different datasets are compared in terms of the frequencies of certain entities or other measurements (see Rühlemann 2011). Quantitative research depends on countable or measurable entities, and such entities depend on the classification of entities gained through qualitative research. In this sense, quantitative research is not possible without a qualitative foundation (see also chapter 18, the introduction to section 5 of this handbook). Qualitative research, on the other hand, appears to be possible without any quantification of its categories, except that the qualitative description of categories in a set of data always makes the, to some extent, quantitative point that this category at least exists in this particular set of data.

In section 2 of this introductory chapter, I will briefly problematize the concept of "naturally occurring", which is often seen as the gold standard for observational pragmatic research. The final section will introduce the four papers of this section of the handbook. For more details on the different types of data in pragmatic 
research the reader is referred to chapter 1 and for a more detailed introduction of corpus pragmatic approaches to chapter 18, which introduces section 5 of this handbook.

\section{The concept of "naturally occurring"}

For many approaches in pragmatics, "naturally occurring" data seem to be some kind of gold standard. Data should be as uncontaminated by any researcher influence as possible. While it is acknowledged that this is an ideal that is hard to achieve, everything should be done to minimise the undesirable effects of researchers' impact on the data. Schegloff (1996: 468), for instance, argues that only "naturally occurring interactional environments which seem to be the natural, primordial home for language use" can serve as data for a conversation analytical research agenda. Have (2007) makes a similar point:

The general CA recommendation for making recordings is that these should catch "natural interaction" as fully and faithfully as is practically possible. The term "natural" in this expression refers to the ideal that the interactions recorded should be "naturally occurring", that is "non-experimental", not co-produced with or provoked by the researcher. [...] In other words, the ideal is to (mechanically) observe interactions as they would take place without research observation, but one can never really verify this. (Have 2007: 68)

The distinction between "naturally occurring" or "authentic" data on the one hand and "contrived" or "researcher prompted" data on the other seems to be relatively clear. It is the distinction between data that "would have occurred anyway without the intervention of the researcher" and data that have been "deliberately elicited by the researcher, by setting up conversations or speaking tasks for the purpose of analysis" (Archer, Aijmer and Wichmann 2012: 12). Potter (2002) makes the same point with his "(conceptual) dead social scientist's test", in which he asks:

Would the data be the same, or be there at all, if the researcher got run over on the way to work? An interview would not take place without the researcher there to ask the questions; a counselling session would take place whether the researcher turns up to collect the recording or not. (Potter 2002: 541; see also Golato 2017: 21, and Golato and Golato, this volume)

He suggests that the term "natural" should be replaced by "naturalistic" because of the many ways in which data generally fall short of the ideal of being entirely natural in the strict sense (Potter 2002: 540). This would then provide a "useful contrast between data that are got up and data that are, at least ideally, not, while recognizing the limits on that distinction" (Potter 2002: 541).

However, even in data that would exist without the intervention of the researcher, there are different levels of "naturalness". The dead social scientist's 
test focuses solely on the impact the researcher has on bringing about the communicative event under observation. There are three additional dimensions or scales along which speech data can be classified as being either naturally occurring or contrived; these concern the purpose of the communicative event, the level of researcher participation in the event and the manner in which it is transformed into a written form as a basis for subsequent inspection and analysis. These dimensions are partly interlinked but they cannot simply be subsumed under the dead social scientist's test.

On the dimension of the purpose of the communicative event, we can distinguish between those speech events that have a purpose outside the research context and those whose purpose is entirely research centred. The counselling session given as an example by Potter in the quotation above has a purpose in itself. Both the counsellor and the client have communicative goals that are not dictated by the research context. In a role play, at the other end of the spectrum, the interactants take part as if play acting. The communicative goals are prescribed by the researcher, and the complaints, requests or apologies acted out in these situations do not have real-world consequences. However, communicative events can also occupy some middle ground between these extremes. In Rüegg's (2014) study of restaurant interactions, for instance, the data consisted of interactions recorded in different types of restaurants in Los Angeles. These interactions were clearly staged for the purpose of the research but they had real-life consequences in that the researcher and her assistants who acted as customers were served drinks and food and were asked to pay for these services. The waiters who served the researcher and her friends arguably interacted with them as they normally interact with restaurant guests in spite of the fact that most of the recorded interactions would presumably not have taken place without the research project.

The next dimension that needs to be considered concerns the researcher's participation or non-participation in the speech event under analysis. Here the spectrum ranges from data that have been produced without any participation and perhaps even without any knowledge of the researcher. The data appear to be most "natural" if the researcher plays no part in the speech event at all. In Labov's (1972: 209) terms, "the aim of linguistic research in the community must be to find out how people talk when they are not being systematically observed, yet we can only obtain these data by systematic observation". According to Labov, this "Observer's Paradox" can be overcome in various ways, for instance by diverting an interviewee's attention away from speech, which will "allow the vernacular to emerge" (Labov 1972: 209). In spite of the success that Labov had with this method, such data would presumably still not count as entirely "natural" or even "naturalistic".

Depending on the type of data being recorded, the researcher's involvement can vary considerably. In some cases, the researcher is a silent observer who tries to behave as unobtrusively as possible, but even in this case his or her presence might affect the speech event under observation. The researcher might be involved 
as one of the participants with a more or less active role in the proceedings with a correspondingly higher influence on the speech event. Or, in the case of role plays, the researcher might even play the role of a movie director who assigns roles and tasks that the participants are supposed to play act. It is difficult to decide at which exact point between the extremes the situation is no longer "natural" and becomes "contrived".

And, finally, the speech situation under observation can only be analysed if at least some aspects are recorded and made permanent. This ranges from field notes to audio and video recordings. Field notes necessarily require the presence of a researcher who observes the situation and decides on the aspects that need to be written down for subsequent analysis. In many cases, field notes have the advantage that they can be taken relatively unobtrusively sometimes even after the event. But field notes can only be extremely selective. The researchers must decide in advance what they want to focus on, and they have to be alert and quick in order not to miss relevant parts while taking notes, and it may be very difficult to remember the crucial aspects of an interaction in the necessary detail. As a result, the field notes might be idealised rather than one hundred per cent accurate.

Recordings are more comprehensive than field notes, especially in the case of video recordings. They are much richer in the details that they capture but their comprehensiveness is also deceptive. Participants in the interaction, perhaps even including the researcher as participant observer, may have background knowledge that allows them to read between the lines of what is going on in the interaction. These may be aspects that fail to show up on recordings made by the impartial technical equipment. Microphones and cameras impose certain perspectives. They highlight some aspects of what is going on and leave others in the dark, often literally.

Ethical considerations are less restrictive for field notes than for recordings. The anonymity of the participants obviously needs to be observed but informed consent is not always necessary if the researcher only takes notes and does not make any audio- or video-recordings. For such recordings informed consent has to be obtained from all participants prior to them being recorded. This requirement in effect rules out that any data can be truly "natural". "From this perspective, then, all data are researcher-prompted and thus contrived" (Speer 2002: 516; emphasis original). This is presumably the reason why Hambling-Jones and Merrison (2012: 1121) argue that surreptitious recordings and retrospective consent might in some situations be superior to pre-obtained consent, but it is doubtful whether the majority of ethical review committees would agree to this position, and in many countries this would be clearly illegal.

Recordings of speech data have to be transcribed to make them accessible to analysis (see Kreuz and Riordan chapter 3, this volume). However, even a very rich and detailed transcription is an idealisation and abstraction of the actual reality that it represents. It imposes the transcriber's perspective on the data and his 
or her decisions about the details that are included and the details that have been omitted. "Transcription is theory. [...] How we transcribe doesn't just reflect our theories of language, it also shapes them, drawing our eyes to some phenomena while leaving others in shadow" (du Bois 1991: 71). As a result, we cannot expect our transcriptions to be an unadulterated representation of reality. A transcription is necessarily a somewhat distorted - or contrived - version of the communicative reality it tries to represent.

Thus, we have to be aware of the many ways in which the pragmaticist's data fail to be truly "natural". Generally, it is more important to carefully assess the limitations of the available data and to evaluate its suitability for specific research questions, rather than to aim for an unrealistic goal (see also Jucker 2009).

\section{The papers in this section}

There are four papers in part 4 of this handbook. In the first paper, Meredith Marra and Mariana Lazzaro-Salazar present ethnographic methods. The term "ethnography" covers a broad range of methods but they all go back to an approach developed by cultural anthropologists. Researchers immerse themselves as much as possible in a community in order to provide detailed, "thick" descriptions of community activities. It is through this participation that the researcher gains a deeper insight into a particular culture and its communicative practices. It provides an analysis that combines an outside perspective (an etic or technical point of view) with an inside perspective (the emic perspective, the point of view of the community members themselves). Marra and Lazzaro-Salazar illustrate ethnographic methods with a discursive approach to politeness in their work on language use in a workplace context. They focus in particular on the prevalent data collection methods, field notes, observations and interviews, and on the different ways of working with such data. At the end of their contribution they also discuss several frequently discussed critiques of ethnographic studies, for instance the critique that ethnographic research can never be sufficiently objective because of the inevitable subjectivity of the data gathering techniques. Further problems are the time commitment that is necessary for data collection and the limited generalisability of the observed patterns beyond the investigated communities.

The paper by Andrea and Peter Golato deals with ethnomethodology, conversation analysis and interactional linguistics, which they describe against a historical backdrop and the seminal work of Erving Goffman, Harold Garfinkel and later Harvey Sacks. Ethnomethodology, conversation analysis and interactional linguistics share most of their underlying assumptions but there are also differences that the authors carefully tease out. Ethnomethodology, for instance, focuses more on how interactants engage in social actions through talk in interaction, while conversation analysis focuses more on the underlying order of talk itself. Both of them 
adopt the perspective of the interactants and investigate how they use language to create meaning. Utterances are not seen in isolation but in the sequential context in which they occur. Conversation analysis and interactional linguistics insist on audio- and video-recorded naturally occurring data that conform to Potter's (2002) dead social scientist's test (see above), and great care is taken with the transcription process that turns the data into written representations. Golato and Golato's outline finishes with a discussion of the range of research topics that have been tackled with the methodologies of conversation analysis and interactional linguistics, a discussion of their strengths and weaknesses, as well as some brief comments on current and future applications of these methods.

Anita Fetzer covers approaches under the general heading of discourse analysis. The two main issues, according to her, are the granularity of the discourse units and the nature of their connectedness. Discourse is seen as a parts-whole configuration in which the whole is more than the sum of its parts. It is the discourse units at whatever granularity they are proposed that form the constitutive elements in the structuring and linearization of discourse. Fetzer also brings in the terms quantity and quality. However, she uses them in a slightly different manner from what has been outlined above. Here, quantity relates to the number of constitutive parts of discourse, i. e. the number of discourse units, while quality relates to the pragmatics of the discourse units, that is to say the way in which they are integrated into their context and connected with neighbouring units. Quantitative studies, therefore, tend to focus on the linear sequence of discourse units and their connectedness, while qualitative studies tend to focus on how interlocutors co-construct and negotiate discourse coherence.

The final paper in this section by Piotr Cap covers Critical Discourse Analysis (CDA). Cap uses the term Critical Discourse Analysis as a cover term for a range of different approaches that vary in their underlying notions and in their research methodology but have in common that they intend to be instrumental in bringing about social change. In this, CDA approaches differ from almost all other linguistic theories, which insist on being descriptive, impartial and detached. CDA is unashamedly partisan. It tries to uncover social injustice and to highlight how language is used to exert institutional power by the elite. Cap teases out the interconnectedness of different branches of CDA and their methodological attractors, that is to say the basic methodologies from which these branches draw their research tools and he discusses the ways in which CDA and pragmatics are related. He also sketches out a CDA model, called a legitimization-proximization model (Cap 2013), which he uses for a case study in which he analyses a speech by U.S. President George W. Bush, given only weeks before U.S. and coalition troops entered Iraq on March 19, 2003. The model helps to unravel the ways in which Bush construes and manipulates closeness and remoteness in the political sphere in order to create credibility and legitimization of the Iraq war and the subsequent anti-terrorist campaigns. 
Thus, in contrast to section 3 of this handbook, which was devoted to various ways of eliciting relevant data for pragmatic research, this section focuses on approaches that deal with pre-existing data. The emphasis is squarely on observation and analysis of what is already there, be it spoken communication or written communication. All contributions in this section focus on approaches that prefer qualitative methods of analysis with an insistence on careful attention to small details and richly contextualised data samples. In this respect, they contrast significantly from the approaches reviewed in the contributions of section 5 of this handbook, which seek generalisations at a higher level and across much larger data sets.

\section{References}

Andersen, Gisle

2011 Corpus-based pragmatics I: Qualitative studies. In: Wolfram Bublitz and Neal R. Norrick (eds.), Foundations of Pragmatics, 587-627. (Handbooks of Pragmatics 1.) Berlin: de Gruyter Mouton.

Archer, Dawn, Karin Aijmer and Anne Wichmann

2012 Pragmatics. An Advanced Resource Book for Students. (Routledge Applied Linguistics.) London: Routledge.

Cap, Piotr

2013 Proximization. The Pragmatics of Symbolic Distance Crossing. (Pragmatics \& Beyond New Series 232.) Amsterdam: John Benjamins.

Du Bois, John W.

1991 Transcription design principles for spoken discourse research. Pragmatics 1(1): 71-106.

Golato, Andrea

2017 Naturally occurring data. In: Anne Barron, Yuego Gu and Gerard Steen (eds.), The Routledge Handbook of Pragmatics, 21-26. London: Routledge.

Hambling-Jones, Oliver and Andrew John Merrison

2012 Inequity in the pursuit of intimacy: An analysis of British pick-up artist interactions. Journal of Pragmatics. Special Issue: Im/politeness across Englishes, 44(9): 1115-1127.

Have, Paul ten

2007 Doing Conversation Analysis. A Practical Guide. Second edition. (Introducing Qualitative Methods.) London: Sage.

Jucker, Andreas H.

2009 Speech act research between armchair, field and laboratory: The case of com-

Labov, William pliments. Journal of Pragmatics 41(8): 1611-1635.

1972 Sociolinguistic Patterns. Philadelphia: University of Pennsylvania Press.

Potter, Jonathan

2002 Two kinds of natural. Discourse Studies 4(4): 539-542.

Rüegg, Larssyn

2014 Thanks responses in three socio-economic settings: A variational pragmatics approach. Journal of Pragmatics 71: 17-30. 
Rühlemann, Christoph

2011 Corpus-based pragmatics II: Quantitative studies. In: Wolfram Bublitz and Neal R. Norrick (eds.), Foundations of Pragmatics, 629-656. (Handbooks of Pragmatics 1.) Berlin: de Gruyter Mouton.

Schegloff, Emanuel A.

1996 Some practices for referring to persons in talk-in-interaction: A partial sketch of a systematics. In: Barbara Fox (ed.), Studies in Anaphora, 437-485. (TypoSpeer, Susan A. logical Studies in Language 33.) Amsterdam: Benjamins.

2002 "Natural" and "contrived" data: A sustainable distinction? Discourse Studies 4(4): 511-525. 